\title{
Effect of hatch window upon intestinal development, chick quality, post hatch performance according to ross-308 broiler breeder age
}

\begin{abstract}
This study was carried out to find out the effects of breeder age on incubation results, intestinal development during hatch window, chick quality and first week broiler performance. A total of $n=259280$ eggs were obtained from commercial Ross-308 broiler breeder flocks at 32 and 52 weeks old, which were equally divided on the basis of breeder age in two groups A (Young 32 weeks), B (old 52 weeks age). These 32 and 52 weeks old flocks, $30 \%$ and $7.0 \%$ were hatched $24 \mathrm{~h}$ before pull time and $50 \%$ and $60 \%$ were hatched $12 \mathrm{~h}$ before pull time, respectively. Hatchability of fertile eggs and hatchability of total eggs were found higher in 32 weeks old flock than the other. The chick hatch weight was determined as $39.5 \mathrm{~g}$ and $42.1 \mathrm{~g}$ in 32 and 52 weeks old flocks, respectively. Chick weight/initial egg weight rate was found to be higher as $67.3 \%$ in the 32 weeks old flocks. On hatching day, chick length was also higher in 52 weeks old flock. Relative yolk-free chick weight was higher in 32 weeks old (86.0\%) flock than the other $(83.0 \%)$. Intestine weight rate was higher as $5.24 \%$ in chicks from 32 weeks old than the other $(4.96 \%)$. At 1 week of age, the body weights and weight gains were $167.5 \mathrm{~g}$ and $162.7 \mathrm{~g}$, and $128 \mathrm{~g}$ and $120.6 \mathrm{~g}$ in 32 and 52 weeks old flocks, respectively. Higher mortality ratio as $1.9 \%$ was observed in 52 weeks old flock. In conclusion, intestinal development during hatch window, incubation parameters, chick quality and first week broiler performance is affected by breeder age.
\end{abstract}

Keywords: ross-308 broiler breeder, hatch window, incubation duration, intestinal development, Post-hatch performance
Volume 7 Issue 6 - 2018

\author{
Adnan Yousaf,' Adnan Jabbar,' Rehana \\ Shahnawaz, ${ }^{2}$ Tahseen Jamil, ${ }^{3}$ Ahmad Hussain, ${ }^{4}$ \\ Mehar-ul-Nissa Rais ${ }^{5}$ \\ 'Salman Poultry (Pvt) Limited, Rawalpindi, Pakistan \\ ${ }^{2}$ Department of Veterinary Pharmacology, Sindh Agriculture \\ University, Pakistan \\ ${ }^{3}$ Department of Veterinary Physiology and Biochemistry, Sindh \\ Agriculture University, Pakistan \\ ${ }^{4}$ Department of Poultry Husbandry, Sindh Agriculture University, \\ Pakistan \\ ${ }^{5}$ Department of Agriculture Economics, Sindh Agriculture \\ University, Pakistan
}

Correspondence: Adnan Yousaf, Salman Poultry (Pvt) Limited, Rawalpindi, Pakistan, Email dr.adnen0I I@gmail.com

Received: February 07, 2018 | Published: December 17, 2018

\section{Introduction}

Poultry is the $2^{\text {nd }}$ largest industry of Pakistan which play a dynamic role in GDP of country. ${ }^{1}$ The value of chicken is further emphasized by its production ability and the increasing demand of its products. ${ }^{2}$ The different phases, from rearing of grandparents stock till the broilers and eggs are marketed, have their own significance. ${ }^{3}$ Chick quality has great importance for broiler breeder producer who is paid based on number of saleable chicks and also broiler producer who wants high-quality, fast growing and uniform broilers. ${ }^{4}$ The chick quality is affected by some factors, such as breeder age, egg size, hatching time and incubation conditions. ${ }^{5}$ The operation and management of hatchery is vital towards the development of quality day old chicks. Various breeding practices and handling of eggs from egg laying to hatching of egg have an influence on the hatchability, particularly storage condition temperature, along with the age of breeding flock have been the most common variable used to manipulate the fertility, hatchability, livability and consequently effect on the quality of day old chick. ${ }^{6}$ The studies have declared that hatching egg quality and incubation conditions significantly influence the post-hatch performance of broilers ${ }^{4-7}$ The incubation period of chicken (Gallus gallus) embryo is approximately (506 hours) 21.08 days including drying down, and the gap among first to last chick hatch time is approximately 12 to 24 hours. ${ }^{8,9}$ This time interval between first and last chick hatch is called "Hatch Window" ${ }^{10}$ In commercial hatcheries incubation times of chicken is approximately 504 hours. $^{7}$ The large scales of chicks pulling are extended up to 510 to 526 hours. Chicks that remained longer in the hatcher show worse live performance. The time period in hatcher after hatching is critical for the development of the gastrointestinal systems and nutrient absorption ${ }^{11}$ Post hatching fasting impairs chick's weight gain and breast muscles deposition capacity. ${ }^{12,13}$ During the first days of the chick's life, the small intestine grows five times faster than the rest of the body, and small intestine microvilli grow significantly faster in birds supplied with water and feed immediately after hatching. ${ }^{7}$ There is a correlation between chick qualities at hatch, broiler performance. ${ }^{14}$ The aim of the current study was to determine the effects of breeder age on incubation results, intestinal development during hatch window, chick quality parameters and first week broiler performance. So in this study, to evaluate the development of intestine, samples were taken during hatch window, in times of $24 \mathrm{~h}$ and $12 \mathrm{~h}$ before pull and at hatch time $(0 \mathrm{~h})$.

\section{Materials and methods}

\section{Experimental site}

The study was carried out at Salman Poultry (Pvt) Limited, Chakri Hatchery Rawalpindi which is situated $5 \mathrm{~km}$ from chakri interchange on motorway (M2). The hatchery contains latest heating ventilation and air conditioning (HVAC) automation. This is the one of largest eggs capacity hatchery of south Asia, which is producing best quality of chicks through single stage incubation system (Avida G4, Chick Master USA).

\section{Selection and handling of eggs}

Eggs (52-60g) from commercial broiler breeders group A (Ross308,32 weeks of age) and Group B eggs (60-64g, 52 weeks of age) with broiler breeder diet with $2750 \mathrm{kcal} \mathrm{ME} / \mathrm{kg}$ and $14.50 \% \mathrm{CP}$ was selected for current study. Both flocks were kept under the same management conditions according to the breeding company's recommendations. Each experimental group was consisting of $n=134640$ eggs, which were graded upon their quality, poor shell, elongated eggs, crack 
were isolated, only standard eggs were set in the incubator machine Advida4 chick master USA. ${ }^{15}$ These eggs were collected at farm at $20^{\circ} \mathrm{C}$ and $75 \%$ relative humidity until used in hatching trial. Before, trial eggs were fumigated with $20 \mathrm{~g} \mathrm{KMnO}_{4}$ and $40 \mathrm{ml}$ formalin (40\%) and $40 \mathrm{ml}$ of water for $100 \mathrm{ft} 3$ areas for 15 minutes through automatic fumigation process provided by Chick Master.

\section{Incubation programme}

Both groups were pre-heated at $82^{\circ} \mathrm{F}$ for 5 hours inside incubators After completion of pre-warming the setter started automatically the age wise incubation stage profile (Recommended by Chicks Master USA). Incubation duration for both groups was remaining same 456 hrs in setter and $50 \mathrm{hrs}$ in hatchers.

\section{Hatchery analyses}

Before transfer to hatchers water loss of both groups' was measured. Water loss was measure after 456 hours as given formula: Water Loss $\% \frac{\text { Full tray weight at Setting-Full Tray Weight at Transfer }}{\text { Full tray weight at Setting- Empty Tray Wight }} \times 100$

Eggs from were transferred to hatchers after $456 \mathrm{hrs}$ of incubation in setter. For both groups during transfer from setter to hatchers candling was performed through candling tables. As hatch out immediately the chick's weight and yield was measure through electrical weight balance by using following formula:

$$
\text { Chick Yield \% } \frac{\text { Weight of chicks }}{\text { Egg weight }} \times 100
$$

Unhitched eggs were opened to macroscopically determine fertility and embryonic mortality (early, middle- and late-term embryonic mortality) Table 1.

Table I Hatch window results of flocks at different ages

\begin{tabular}{llll}
\multirow{2}{*}{ Group } & \multicolumn{3}{l}{ Chicks hatch out \% after incubation duration } \\
& After 482 hrs & After 492 hrs & After 506 hrs \\
\hline A Young (32 weeks) & $30 \%$ & $50 \%$ & $23 \%$ \\
B Old (52 weeks) & $7 \%$ & $60 \%$ & $27 \%$ \\
\hline
\end{tabular}

\section{Hatch window and intestine analysis}

The hatched chicks in time of 482h, 492h and 503-506h were counted, and the rate of hatching chicks according to these times was calculated. In these times, after chicks were counted, chicks were transferred to another hatching basket. During hatch window, to determine development of intestine, chicks ( $\mathrm{n}=20$ chicks/sampling time/breeder. age) were randomly sampled in the sampling times [24 $\mathrm{h}$ before pull time $(-24 \mathrm{~h}), 12 \mathrm{~h}$ before pull $(-12 \mathrm{~h})$ and at hatch $(0 \mathrm{~h})]$. In sampling times for $-24 \mathrm{~h}$ and also $-12 \mathrm{~h}$ before pull time, chicks were randomly sampled from hatcher. The sampled chicks were weighed and killed by cervical dislocation, and then the intestine was dissected. The intestine weight and length were measured, and the ratio of intestine weight to chick weight was calculated. The length of intestine was measured from the beginning of small intestine to the end of the cloaca.

\section{Hatch pulling}

Hatch pulling was performed through conventional method of hatch pulling in Pakistan. First pull at 494 hour ( 456 hrs in setters and $38 \mathrm{hrs}$ in hatchers. For second hatch pull the remaining pips and unhatched eggs were again shifted to hatcher for next $12 \mathrm{hrs}$. After 12 hrs again pulling of un-hatch eggs was performed to determine the effects of incubation results on intestinal development during hatch window. Grading of chicks was performed on conveyer, automatic grading table. Only stranded (shining eyes, soft legs and nose, healed naval and healthy chicks) were shifted to chick's box after counting, while under weight, weak, and unhealed naval chicks were removed as international standard.

\section{Analysis of residual yolk in chicks}

Chicks from each group were measured for chick weight and chick length and then killed by cervical dislocation to determine residual yolk sac weight and yolk-free chick weight. Chick length was measured from the tip of the beak to the tip of the longest toe by placing the chick face down on a flat surface and straightening the left leg.

\section{Delivery to poultry house}

Total $n=56,000(A n=28000, B n=28000)$ day old chicks were send to salman broiler farm Khilari-Chakri, Rawalpindi. Environmentally control vehicles $\left(75{ }^{\circ} \mathrm{F}\right.$ temperatures, $65 \%$ humidity) are used to deliver the chicks to control poultry house in the 102 chicks/box with dimensions of plastic chick's box (27x19.5x6.5 inches). Poultry house condition was remained same for both groups. At farm, chicks of both groups were offered water and feed diets (3020Kcal ME/ $\mathrm{kg}, 22 \% \mathrm{CP}$ ) ad libitum. The diet was formulated according to the recommendations of the NRC using windows user-Friendly feed formulation (WUFFDA) software program. Intake of feed and water was record daily, while body weight and total feed consumed were recorded on weekly basis. After 07 days chicks' weights were measured for both group, mortality was recorded during the first week. For ventilation Viper Touch (Big Dutchman, Co., Germany) system was installed.

\section{Statistical analyses}

All data were analyzed by using Statistical Analysis System package software (SAS version 9.2, SAS Institute Inc., Cary, NC, USA). All means were compared using Duncan's Multiple Range test and results were presented as mean \pm SEM (standard error of mean). Results were considered significant if exist $(\mathrm{P}<0.05)$.

\section{Results}

The hatch window results of 32 and 52 weeks old broiler breeder flocks are presented in Table 1. Hatch window was found that $30 \%$ and $7.0 \%$ of the chicks were hatched in the time of $482 \mathrm{~h}, 50 \%$ and $60 \%$ of the chicks between $492 \mathrm{~h}$, and $23 \%$ and $27 \%$ of the chicks between $504 \mathrm{~h}$ to $506 \mathrm{~h}$ in 32 and 52 weeks old broiler breeder flocks, respectively. Incubation period was completed in 504h in 32 weeks old breeder flock, whereas it was completed in $510 \mathrm{~h}$ in 52 weeks old breeder flock. The effects of breeder age on incubation results and cloacal temperature are presented in Table 2. The effects of breeder age on egg weight was found to be significant $(\mathrm{P}=0.001)$. Egg weight was $57.1 \mathrm{~g}$ and $63.7 \mathrm{~g}$ in 32 and 52 weeks old flocks, respectively. Fertility was similar in breeder age groups, whereas hatchability of fertile eggs and hatchability of total eggs were found to be higher in 32 weeks old flock than the other $(\mathrm{P}=0.001)$. Hatchability of fertile eggs and hatchability of total eggs were $90.1 \%$ and $87.67 \%$ in 32 and 52 weeks old flock, respectively. Early, middle- and late-term embryo dead and cull chick rate were found to be higher in 52 weeks old flock $(\mathrm{P}=0.001)$. The cull chick rate was $0.81 \%$ and $1.7 \%$ in 32 and 
52 weeks old flocks, respectively. Water loss was found higher with a rate of $13.1 \%$ in 52 weeks old flock than the other $(\mathrm{P}=0.001)$. Chick hatch weight was $39.5 \mathrm{~g}$ and $42.1 \mathrm{~g}$ in 32 and 52 weeks old flocks, respectively $(\mathrm{P}=0.015)$. Chick weight/initial egg weight rate was found to be higher with a value of $68.3 \%$ in the 32 weeks old flock $(\mathrm{P}=0.035)$. The cloacal temperature was found to be similar between flocks $(\mathrm{P}=0.058)$. The effects of breeder age on the development of intestine development during hatch window are presented in Table 3. The intestine weight rate was only found to be significant in breeder age groups. It was higher with a value of 5.24\% in chicks from 32 weeks old flock than the other $(4.96 \% ; \mathrm{P}=0.046)$. During the hatch window, the chick weight, the weight and length of intestine and the intestine weight ratio were similar in sampling times. The effects of breeder age on the chick weight, chick length, residual yolk sac weight, relative residual yolk sac weight, yolk-free chick weight and relative yolk-freechick weight are presented in Table 4. On hatching day, chick weight and length were found as $39.5 \mathrm{~g}$ and $42.1 \mathrm{~g}$, and $18.5 \mathrm{~cm}$ and $19.4 \mathrm{~cm}$ in 32 and 52 weeks old flocks, respectively. Higher residual yolk sac weight and relative residual yolk sac weight were observed in 52 weeks old flock with a value of $7.1 \mathrm{~g}$ and $18.2 \%$. Although yolk-free chick weight was similar between flocks, relative yolk-free chick weight was higher in 32 weeks old flock (86.0\%) than the other $(83.0 \%)$. The effects of breeder age on the post-hatch first week broiler performance parameters are presented in Table 5. The initial body weight on day 1 was higher in the 52 weeks old flock $(42.1 \mathrm{~g})$ than the 32 weeks old flock $(39.5 \mathrm{~g})$. At 1 week of age, the body weights and body weight gains were determined as $167.5 \mathrm{~g}$ and $162.7 \mathrm{~g}$, and $128 \mathrm{~g}$ and $120.6 \mathrm{~g}$ in 32 and 52 weeks old flocks, respectively. Feed consumption and feed conversion rate were similar between treatments for the first week. Higher mortality ratio as $1.9 \%$ was observed in 52 weeks old flock.

Table 2 The effects of breeder age on incubation results

$\begin{array}{llll}\text { Incubation results } & \text { 32 week } & \text { 52 week } & \text { P Value } \\ \text { Egg weight (g) } & 57.1 \pm 1.4 & 63.7 \pm 1.5 & 0.001 \\ \text { Fertility (\%) } & 95.2 \pm 0.8 & 96.0 \pm 0.9 & 0.001 \\ \text { Hatchability of fertile eggs (\%) } & 90.1 \pm 2.5 & 87.67 \pm 2.1 & 0.001 \\ \text { Hatchability of total eggs (\%) } & 88.3 \pm 1.3 & 84.2 \pm 2.2 & 0.001 \\ \text { Early term embryo dead (\%) } & 2.2 \pm 0.5 & 4.0 \pm 1.4 & 0.001 \\ \text { Middle-term embryo dead (\%) } & 0.88 \pm 0.4 & 1.7 \pm 0.4 & 0.001 \\ \text { Late-term embryo dead (\%) } & 4.2 \pm 1.4 & 6.6 \pm 1.5 & 0.001 \\ \text { Cull chicks (\%) } & 0.81 \pm 0.3 & 1.7 \pm 0.2 & 0.001 \\ \text { Water loss (\%) } & 11.2 \pm 1.1 & 13.1 \pm 1.2 & 0.001 \\ \text { Chick hatch weight }(\mathrm{g}) & 39.5 \pm 1.2 & 42.1 \pm 1.0 & 0.015 \\ \text { Chick weight/initial egg weight }(\%) & 67.3 \pm 1.2 & 65.2 \pm 1.4 & 0.035 \\ \text { Total incubation period (h) } & 504 & 510 & \\ \text { Cloacal temperature }\left({ }^{\circ} \mathrm{C}\right) & 38.8 \pm 1.7 & 39.0 \pm 1.5 & 0.058\end{array}$

Table 3 The effects of breeder age on intestinal development during hatch window

\begin{tabular}{lllll}
\hline Breeder age (weeks) & Chick weight (g) & Intestine weight (g) & Intestine weight rate (\%) & Intestine length (cm) \\
\hline 32 & 39.5 & 2.07 & 5.24 & 39.9 \\
52 & 42.1 & 2.09 & 4.96 & 41.2 \\
Sampling time (h) before hatch & & & 4.24 \\
-24 & 40.8 & 2.14 & 5.09 & 41.3 \\
-12 & 40.6 & 2.07 & 5.13 & 41 \\
0 & 40.1 & 2.06 & & 40.7 \\
Age X Time & & 5.31 & 40.5 \\
32 X -24 & 39.7 & 2.11 & 5.27 & 41 \\
32 X - 12 & 39.4 & 2.08 & 5.28 & 41.6 \\
32 X 0 & 39.2 & 2.07 & 5.03 & 41.4 \\
52 X -24 & 42.3 & 2.13 & 5.28 \\
52 X -12 & 39.9 & 2.11 & 5.3 \\
52 X 0 & 40 & 2.12 & 41.5 \\
\hline
\end{tabular}

Table 4 Breeder age effect upon yolk of chick

\begin{tabular}{lll}
\hline Characteristics & 32 week & 52 week \\
\hline Chick weight $(\mathrm{g})$ & $39.5 \pm 0.56$ & $42.1 \pm 0.52$ \\
Chick length $(\mathrm{cm})$ & $18.5 \pm 0.3$ & $19.4 \pm 0.3$ \\
Residual yolk sac weight (g) & $5.7 \pm 1.15$ & $7.1 \pm 1.75$ \\
Relative residual yolk sac weight (\%) & $15.3 \pm 2.5$ & $18.2 \pm 2.1$ \\
Yolk-free chick weight (g) & $32.5 \pm 1.5$ & $33.3 \pm 1.7$ \\
Relative yolk-free chick weight (\%) & $86 \pm 0.5$ & $83 \pm 0.5$
\end{tabular}

Table 5 Post hatch performance of first week broiler parameters for breeder ages

\begin{tabular}{lll}
\hline Parameters & 32 week & 52 week \\
Initial weight, g/bird & $39.5 \pm 0.2$ & $42.1 \pm 0.2$ \\
Body weight, g/bird & $167.5 \pm 1.2$ & $162.7 \pm 1.2$ \\
Body weight gain, g/bird & $128 \pm 2.2$ & $120.6 \pm 2.5$ \\
Feed consumption, g/bird & $116 \pm 3.2$ & $118 \pm 3.5$ \\
Feed conversion ratio (FCR) & $0.95 \pm 0.5$ & $1.05 \pm 0.5$ \\
Mortality & 0.85 & 1.9 \\
\hline
\end{tabular}




\section{Discussion}

This study has investigated the effects of breeder age on incubation results, intestinal development during hatch window, chick quality parameters and first week broiler performance. In 52 weeks old flock, the actual hatching rate at $-12 \mathrm{~h}$ and $-24 \mathrm{~h}$ of pull time was lower than expected, so it caused longer time range between the first and last hatched chicks. In other studies, hatch window range was found as $24-48 \mathrm{~h},{ }^{16} 28 \mathrm{~h}{ }^{12}$ and $30 \mathrm{~h} .{ }^{9}$ Similarly, it was observed that eggs laid by 32-week-old breeders hatched $9 \mathrm{~h}$ early than those laid by 52 -weekold breeders. ${ }^{17}$ In this study, egg weight was $57.1 \mathrm{~g}$ and $63.7 \mathrm{~g}$ in 32 and 52 weeks flocks, respectively. The time required for hatching increased in heavy eggs as compared to lighter eggs of older age breeders. In this study, the hatchability of fertile eggs and hatchability of total eggs of old breeders' eggs were lower than those of young breeders, which were found significantly different. In this study, higher ratio of embryo mortalities was observed in older flock. Rate of cull chicks (\%) was found to be higher as $1.7 \%$ in 52 weeks old group. The reason of higher rate of cull chicks in 52 weeks old group could be attributed to longer hatch window. The average egg weight loss should be between $11.5 \%$ and $13 \%$ to obtain the highest hatchability of chicken eggs. Weight loss was higher as $13.1 \%$ in 52 weeks old flock. Chick hatch weight and chick weight/initial egg weight rate were found to be significant. Chick hatching weight was found higher in 52 weeks old flock, and chick weight/initial egg weight rate was affected by breeder age. Embryo uses the nutrients from the yolk sac to initiate body growth, ${ }^{18}$ for development of the small intestine and other organs. Residual yolk sac comprises approximately $14 \%$ of the chick's body weight at the time of hatching. ${ }^{18}$ Before hatching; absorption of the yolk sac into the abdomen of the embryo provides nutrients for the chicks during the first few days of life. Chick weight is a combination of the real chick weight and the remaining yolk residual. On the hatching day, the residual yolk sac weight and relative residual yolk sac weight were found higher as $7.1 \mathrm{~g}$ and $18.2 \%$ in old flock, respectively. After subtracting yolk sac weight from chick weight, there were no differences between groups. Relative yolk-free chick weight was found to be higher in young flock. The quality of the day-old chick is important for a good start of the chick and also for the final performance of broiler. ${ }^{18}$ Breeder age, egg weight, egg age, climatic conditions of both hatchery spaces and incubators, and some other factors predominantly affect hatch window and therefore chick quality. ${ }^{19}$ On hatching day, chick weight and length were found as $39.5 \mathrm{~g}$ and $42.1 \mathrm{~g}$, and $18.5 \mathrm{~cm}$ and $19.4 \mathrm{~cm}$ in 32 and 52 weeks old groups, respectively. In this study, heavier and longer chicks in old flock were resulted from heavier egg weight. It was stated that chick length has a substantially higher positive correlation with broiler performance than day old chick weight, especially when corrected for egg size. ${ }^{18}$ Initial body weight was lower in young flock, after 1 week post-hatch, body weight and body weight gain were found higher than old flock. It could be explained by yolk sac absorption, and development of intestine of the chicks in this group was higher than the other. Intestine weight was heavier in chicks from young than from old flock in this study. Feed consumption and feed conversion rate were not influenced by breeder age. The mortality during first week was found significantly higher as $1.9 \%$ in 52 weeks old flock. The time range after hatching is vital for the development of immune and gastrointestinal systems. While early term chick feeding stimulated the development of bursa and production of lymphocytes, ${ }^{20}$ long fasting times stimulate corticosterone production that has a strong inhibitor effect on immune cells. These cause a decrease in growth rate and an increase in early term chick mortalities. ${ }^{16}$

\section{Author's contribution}

All authors contribute equally in this research study.

\section{Acknowledgments}

None

\section{Conflicts of interest}

The author declares that there are no conflicts of interest.

\section{References}

1. Hussain J, Rabbani I, Aslam S, et al. An overview of poultry industry in Pakistan. World Poult Sci J. 2015;71(4):689-700.

2. Anonymous. Food and Agriculture Organization of the United Nations FAOSTAT. 2011

3. Khan MJ. Effect of storage, preheating, and turning during storage on Hatchability, $1^{\text {st }}$ Edition. 2011

4. Yousaf A, Jabbar A, Ditta YA. Effect of pre-warming on broiler breeder eggs hatchability and post-hatch performance. J Anim Health Prod. 2017;5(1):1-4.

5. Jabbar A, Yousaf A. Effect of age wise incubation programme on broiler breeder hatchability and post hatch performance. Online J Anim Feed Res. 2017;7(1):13-17.

6. Koka TD. Effect of storage and pre heating during storage on hatchability. Poultry Science. 2002;12(8):21-23.

7. Almeida JG, Vieira SL, Gallo BB, et al. Period of Incubation and Posthatching Holding Time Influence on Broiler Performance. Brazilian Journal of Poultry Science. 2006;8(3):153-158.

8. Romanini CEB, Exadaktylos V, Tong Q, et al. Monitoring the hatch time of individual chicken embryos. Poultry Sci. 2013;92:303-309.

9. Van de Ven LJF, Wagenberga V, Debonne M, et al. Hatching system and time effects on broiler physiology and posthatch growth. Poult Sci. 2011;90(6):1267-1275.

10. Tong Q, Romanini C, Exadaktylos V. Embryonic development and the physiological factors that coordinate hatching in domestic chickens. Poult Sci. 2013;92:620-628.

11. Yalcin S, Izzetoglu GT, Aktas A. Effects of breeder age and egg weight on morphological changes in the small intestine of chicks during the hatch window. Brit Poultry Sci. 2013;54(6):810-817.

12. Careghi C, Tona K, Onagbesan O, et al. The effects of the spread of hatch and interaction with delayed feed access after hatch on broiler performance until seven days of age. Poultry Sci. 2005;84(4):1314 1320 .

13. Halevy O, Geyra A, Barak M, et al. Early posthatch starvation decreases Satellite cell proliferation and skeletal muscle growth in chicks. Journal of nutrition. 2000;130(4):858-864.

14. Ipek A, Sozcu A. The effects of broiler breeder age on intestinal development during hatch window, chick quality and first week broiler performance. Journal of Applied Animal Research. 2015;43(4):402-408.

15. Yousaf A. Impact of gender determination through vent sexing on Cobb-500 broiler performance and carcass yield. Online J Anim Feed Res. 2016;6(6):125-129. 
16. Decuypere E, Tona K, Bruggeman V, et al. The day-old chick: a crucial hinge between breeders and broilers. World's Poultry Sci J. 2001;57(2):127-138.

17. Pedroso AA, Stringhini JH, Leandro NSM, et al. Desempenho e biometria de órgãos digestórios de frangos provenientes de matrizes jovens após Posthatching HoldingTime Influence on Broiler Performance. Brazilian Journal of Poultry Science. 2005;8(3):153-158.

18. Meijerhof R. The influence of incubation on chick quality and broiler performance. In: Proceedings of $20^{\text {th }}$ Annual Australian Poultry Science Symposium. 2009.
19. Vargas FSC, Baratto TR, Magalhaes FR, et al. Influences of breeder age and fasting after hatching on the performance of broilers. $J$ Appl Poultry Res. 2009;18(1):18-24.

20. Bigot K, Tesseraud S, Taouis M. The relation of egg weight to chick weight at hatching. Poultry Science. 2001;1(4):219-230. 